PRODUCTION

ENGINEERING

ARCHIVES
2015, Vol. 6, No 1, pp 35-38

ISSN 2353-5156 (print version)

ISSN 2353-7779 (online version)

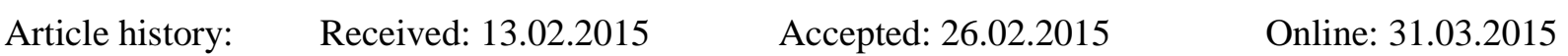

Available online on: http://www.qpij.pl

Exist since $1^{\text {th }}$ quarter 2013

\title{
The dynamic state monitoring of bearings system
}

\author{
Marek Krynke $^{1}$ \\ ${ }^{1}$ Institute of Production Engineering, Faculty of Management, Czestochowa University of Technology, Armii Krajowej 19B, \\ 42-201 Czestochowa, Poland, e-mail: krynke@zim.pcz.pl
}

\begin{abstract}
The article discusses the methods of dynamic state monitoring of bearings system. A vibration signal contains important technical information about the machine condition and is currently the most frequently used in diagnostic bearings systems. One of the main advantages of machine condition monitoring is identifying the cause of failure of the bearings and taking preventative measures, otherwise the operation of such a machine will lead to frequent replacement of the bearings. Monitoring changes in the course of the operation of machinery repair strategies allows keeping the conditioned state of dynamic failure conditioned preventive repairs and repairs after-failure time. In addition, the paper also presents the fundamental causes of bearing failure and identifies mechanisms related to the creation of any type of damage.
\end{abstract}

Key words - rolling bearings, Vibration diagnostics

\section{Introduction}

Diagnostic surveillance systems use signals generated in bearing nodes supervised by machine. From the viewpoint of bearings diagnosis it is important to control as often as possible the dynamic state of machine changes in bearing nodes, in order to determine the type of damage and the degree of its advancement. This approach avoids the effects of unexpected breakdowns of machinery and early enough to take appropriate preventative and corrective action. Monitoring the dynamic state of bearings nodes can carry out repairs that result from the current machine technical condition, which also allows for abandonment, sometimes premature, preventative repairs related to the working time of the machine and after emergency repairs in the event of failure (CEMPEL C. 2008,
ŻóŁTOWSKI B. 1996, KRYNKE M., SELEJDAK J., BORKOWSKI S. 2012).

Performing repairs, based on the machine state allows one to determine the optimal time needed for maintenance, saving money, incurring costs related to unnecessary maintenance and unexpected failures. Maintenance of the machine based on the monitoring of their condition is the cheapest method of machines operation and frees up performance repairs of the machine if required by their technical condition (SWȨDROWSKI L. 2010).

Rolling bearings easily transfer vibration to housing, with the result that their operation produces a high level of noise, which is a drawback from the point of view of the machine construction. This noise can however, be used as a diagnostic signal, which allows for the monitoring of the technical condition of bearing normal operation, without the need to dismantle the 
device (KRZEMIŃSKI-FREDA, H., WARDA, B. 1989, PORADNIK CX BEARINGS 2014).

\section{Damage of rolling bearings}

Damage of bearings manifested in loss or deformation of their mass results in complete destruction of the bearing. Under normal operating conditions the load-balanced occur as a result of material fatigue damage. These defects are generally in the form of cracks located under the surface of raceway, and rolling elements, which gradually increase in contributing to the generation of additional vibrations (Fig. 1) and an increase in noise level during bearing operation. Further exposure of bearings leads to the appearance of cracks resulting in surface enucleation of raceways and rolling elements. Expanding enucleation leads to contamination of the lubricant and causes local overloads around the perimeter of raceway, which results in uneven bearing operation (MAZANEK E., KRYNKE M. 2011, KRYNKE M., SELEJDAK J., BORKOWSKI S. 2012, KRYNKE M., KonOP K., MiELCZAREK K. 2014).

The formation of damage and acceleration of this process is affected by many different factors. Generally, the source of bearings damage can be divided into two groups (SZYMANIEC S. 2007, PRZEGLĄD MECHANICZNY. 2011):

- natural damage,

- premature damage.

Natural damage results from wear and excess nominal durability. However, the causes of premature damage are many and can be distinguished here:

- incorrectly performed installation process (this is the most common cause of premature bearing failures). Generally it is a seal damage, bad or inaccurate screw flange fitting performance,

- incorrectly carried out production process - inadequate finish grinding elements or inadequate heat treatment,

- bearing node construction errors - for example, significant slack in the housing and failed fitting, inadequate selection of bearings for conditions (overload bearings), wrong housing cross section or bad geometry,

- external conditions directly affecting the operation of bearing - for example, corrosion, external vibration electrical current to flow,
- inadequate structural node support

The bearing wear after the first symptom to total destruction proceeds in the following three steps (KANIA L., KRYNKE M., MAZANEK E. 2012):

1. noise phase,

2. vibration phase,

3. thermal phase.

The first stage -the noise phase - lasts from the beginning of the bearing operation to the first appearance of macro defects. It reveals a broadband noise whose peak value about amplitude of vibration acceleration is at the level of $0,1 \div 0,2 \mathrm{~g}$.

The second stage -Vibration phase - occurs after noise phase and is the result of increasing mass loss. This lowers the acceleration value and average vibration frequency.

In the last stage - thermal phase - there are growing losses and deformation resulting in increased motion resistance, formed a strong friction, causing the bearing temperature to rise (KANIA L. 2006).

\section{Diagnostic methods of bearing}

Bearings diagnostics based on measuring and analyzing diagnostic signals are generated as a result of damage or incorrect installation of the bearings. The diagnosis of rolling bearings is used in a variety of methods based on physical grounds. Usually these are measurements of vibration, temperature, acoustic phenomena and electricity (KRYNKE M., KANIA L., MAZANEK E. 2012). The commercially available diagnostic devices generally use methods of bearing vibration.

\subsection{Measurements of the general vibration level of bearings nodes}

Methods based on the measurement of emitted vibrations, based on tracking the tendencies of vibration level changes in a wide frequency band $(10 \mathrm{~Hz}$ to $10 \mathrm{kHz}$ ) over time (Fig. 1). Bearings Vibration limits are specified in the relevant standards (PN-90 N01358). The advantages of these methods are to apply for machine condition based on a single measurement, simple operation and low price tooling. These methods do not allow for accurate determination of the damage type, they do not allow the development of estimates further development of the damage. Data obtained 
from measurements generally have a high ambiguity. This is due both to susceptibility to interference from other sources of vibration, as well as major difficulties in symptom assessment at low amplitude test signals. Difficulties in location causes of excessive vibration levels make these methods used in the initial diagnosis of rolling bearings.

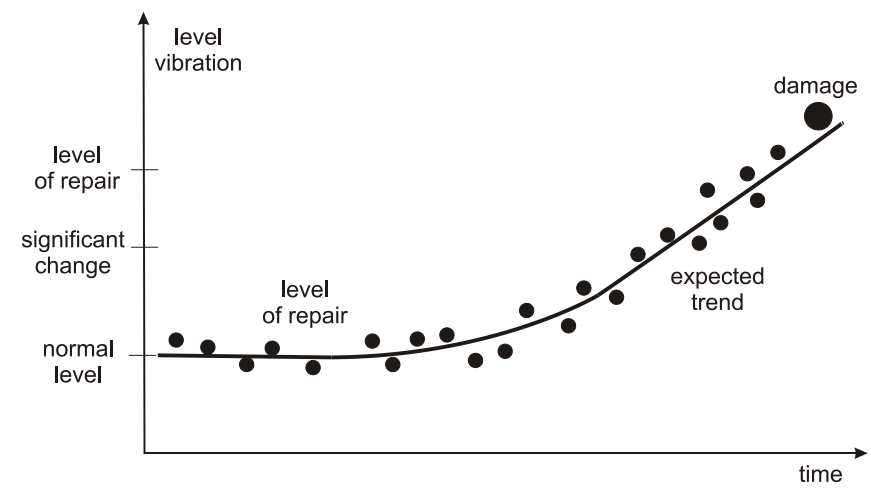

Fig. 1. An example of broadband vibration level changes trend [6].

Source: own study.

\subsection{Shock pulse measurement}

If in the bearing there is metallic contact mating surfaces, the discrete forces are generated as a result, reflecting in the time course of Bearings vibrations in the form of characteristic "shock pulse”. The width of these pulses is dependent on the nature of the damage and working conditions of the bearing. These pulses are generally too small to raise areas of machine vibration in the tens of $\mathrm{kHz}$. Observation of own vibrations area allows the isolation of impulse from the general vibration signal, which allows the diagnosis of bearings condition on the basis of the shock pulse(MAKOWSKI R, ZIMROZ R. 2012).

This method allows one to obtain good results in the assessment of the technical condition of bearings but has two drawbacks. The first disadvantage is the need for separate diagnostic signals from interference from other sources than the bearing. The second disadvantage of this method is the lack of repeatability characteristics of bearings nodes mobility, making it necessary to search for individual areas of own vibrations, even for nodes with the same structure. Among bearings diagnostic methods, based on the measurement of the shock pulse can be distinguished:
a) SPM,
b) peak factor measurement,
c) kurtosis measurement.

The method of SPM (Shock Pulse Method) (Fig. 2) assessment of the bearing is to compare current measured impact speed level with the level specified for the bearing operating properly. This method has the ability to analyze the trend, and the possibility of early detection of damage. The disadvantage is the high dependence of the results of measurements of the transducer mounting method and the inability to identify the type of bearing damage. Consequently, based on the results of measurements by SPM it can't estimate a time of machine operation failure. Another disadvantage of this method is the fact that in low-speed machines (speeds of 50 - $100 \mathrm{rpm} / \mathrm{min}$ ) in the undamaged bearings are shock pulse. Diagnosis of this type of machine SPM method gives less accurate results.

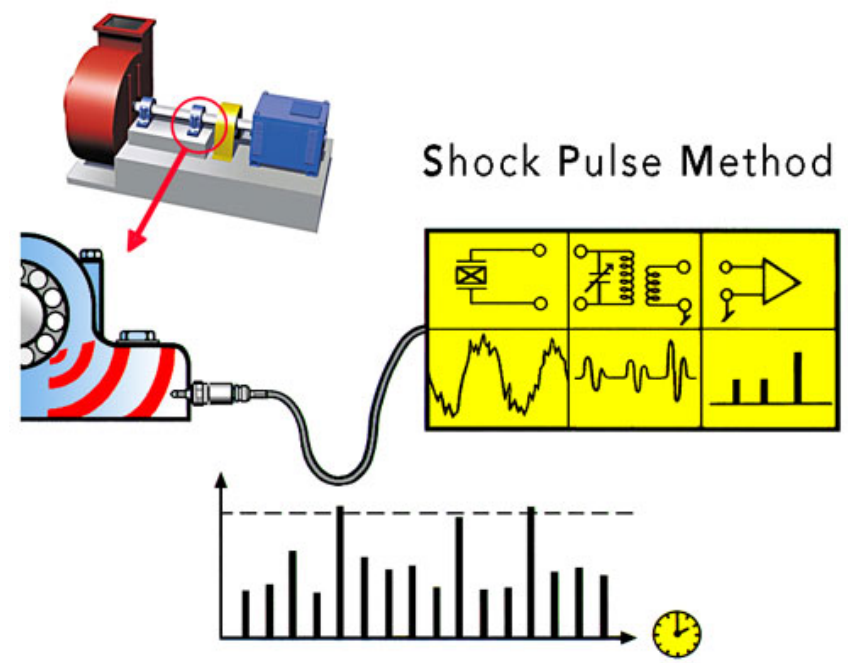

Fig. 2. Processing shock pulse signals.

Source: own study.

The peak factor measurement method is based on an examination of the ratio of the peak signal to the RMS value in the frequency range [6]. Most commonly vibration acceleration is measured:

$$
\mathrm{C}=\frac{\hat{\mathrm{a}}}{\mathrm{a}}
$$

where: $\hat{a}$ - peak value of vibration acceleration amplitude,

ã - RMS vibration acceleration amplitude.

In this method, it is important to observe changes over time - increase of the ratio value points to the deterioration of the bearing condition. The disadvantage of this method is the need to perform measurements at the start of the bearings operation in order to determine the trend of damage and estimate a operating time to failure. This estimate is not very precise. 
Kurtosis measurement is a statistical method based on the measurement of the coefficient of kurtosis (,impulsivity”) $\mathrm{K}$ vibration acceleration signal. A practical estimator of the process is described by the following relation $[16,17]$ :

$$
\mathrm{K}=\frac{\mathrm{E}(\mathrm{x}-\mathrm{u})^{4}}{\sigma^{2}}
$$

where: $\mathrm{E}$ - estimator of the expected value,

$$
\begin{aligned}
& \mathrm{x} \text { - random variable, } \\
& \mathrm{u}-\text { average value, } \\
& \sigma-\text { standard deviation. }
\end{aligned}
$$

For a Gaussian distribution of signal amplitudes, dimensionless coefficient $\mathrm{K}$ is equal to 3 . If kurtosis has a value greater than 3 , it may be a flattening of the distribution which is probably associated with the presence of the signal pulse in time. The size of coefficient $\mathrm{K}$ is dependent on the frequency range in which the measurement is made. It does not depend on the speed and load of bearing. The method allows the assessment of the bearing damage without the knowledge of the history of the operating unit. To assess the state of bearing, usually a single measurement is sufficient. The disadvantage of this method is that if a pulse signal other than from the bearing, it is not usually possible to achieve good results of diagnostic [16].

\section{Summary}

In this article, methods of bearings diagnosis were discussed but do not exhaust all possible ways of diagnosis occurring in practice. They are, however, representative of the current state of knowledge in the diagnosis of rolling bearings in most machines.

A vibration signal contains important technical information about the technical state of machine and is currently the most widely used in diagnostic bearings systems. Therefore, methods based on vibration measurements are best developed and provide reliable results. In some cases, such as when there is no direct access to the device, these methods can't be used. It should also be noted that some of the methods vibration drawback is the need for the advancement of diagnostic methods of separating signals from interference from other sources than the bearing and complex vibration signal analysis algorithms, or the need to perform measurements at the start of use of bearing.

\section{Literature}

1. CEMPEL, C. 2008. Decomposition of symptom observation matrix and its optimization in vibration condition monitoring of machines. Applied Mechanics and Materials, Volume 9, Pages 51-60.

2. KANIA L. 2006. Modelling of rollers in slewing bearing calculations with the use of finite elements. Mechanism and Machine Theory, 41 (2006), 11: 1359-1376.

3. KANIA L., KRYNKE M., MAZANEK E. 2012. A Catalogue Capacity of Slewing Bearings. Mechanism and Machine Theory, Vol.58. s.29-45.

4. KrynKe M., KANiA L., MAZANEK E. 2012. Modelling the contact between the rolling elements and the raceways of bulky slewing bearings. Key Engineering Materials, Vol. 490 s.166-178.

5. KRYNKE M., KONOP K., MiElCZAREK K. 2014. Identifying variables that influence manufacturing product quality. Production Engineering Archives. Vol. 4(3)/2014. s.

6. Krynke M., Selejdak J., Borkowski S. 2012. Diagnosis and damage of bearings. Manufacturing Technology. (12), p. 140-144.

7. Krynke M., Selejdak J., Borkowski S. 2012. The Analysis of Damage to Pitch Surfaces of Slewing Bearings. Advanced Manufacturing and Repair Technologies in Vehicle Industry. 29th International Colloquium. EDIS - Editing Centre ZU. Zilina s. 71-75.

8. KRZEMIŃSKI-FREDA, H., WARDA, B. 1989. The effect of roller end-flange contact shape upon frictional losses and axial load of the radial cylindrical roller bearing. Tribology Series. Volume 14, Issue C, , Pages 287-295.

9. MAKOWSKI R, ZIMROZ R. 2012. A procedure for weighted summation of the derivatives of reflection coefficients in adaptive Schur filter with application to fault detection in rolling element bearings. Mechanical Systems and Signal Processing.

10. MAZANEK E., KRYNKE M. 2011. Uszkodzenia bieżni łożysk wieńcowych. Tribologia. Teoria i praktyka. Oficyna Wydawnicza SIMP. 3/2011 (37). Warszawa. s.67-80.

11. PN-90 N-01358, Metody pomiarów i oceny drgań maszyn.

12. PORADNIK CX BEARINGS: http://e-katalog.home.pl/ CX_BEARINGS/poradnik.php?gr=5\&pod=17\&sub=1.

13. PRZEGLĄD MECHANICZNY. 2011. Uszkodzenia łożysk i ich przyczyny. nr 11/11.

14. SWȨDROWSKI L. 2010. Current measurements and analysis for induction motor diagnostics. Metrology and Measurement Systems. Volume 17, Issue 1.

15. SZYMANIEC S. 2007. Assessment of the condition of rolling bearings in electric motors. Archives of Electrical Engineering. Volume 56, Issue 221-222, Pages 299316.

16. ŻóŁtowski B. 1996. Podstawy diagnostyki maszyn. Wydawnictwo Uczelniane ATR, Bydgoszcz. 